\title{
Review Essay: Comparing Demographic and Sociological Imaginations
}

Paul Spoonley, The New New Zealand. Facing Demographic Disruption, Massey University Press, Auckland, 2020.

Richard Alba, The Great Demographic Illusion: Majority, Minority, and the Expanding American Mainstream, Princeton University Press, Princeton, 2020.

David Pearson

Victoria University of Wellington

\begin{abstract}
Paul Spoonley's wide-ranging survey of what he sees as new local population challenges is described and assessed. This is followed by an examination of Richard Alba's critical analysis of how the misuse of demographic statistics influenced recent American political upheavals and distorts an understanding of ethno-relations in the United States. Whether his theory of new non-zero assimilation can be applied to New Zealand is then tentatively explored. Finally, some reflections on the relationship between demography and sociology and the enduring dangers of categoricalism are presented.
\end{abstract}

Key Words: Aotearoa New Zealand, USA, Demography, Sociology, Social Aspects of Population 


\section{A New New Zealand?}

I suspect many readers only glance at acknowledgements if, indeed, they read them at all. In this instance, they are noteworthy for what they reveal about these authors' relationship to closely related but different disciplines. In his appreciation of those who assisted the writing endeavour, Paul Spoonley modestly confesses that he is 'not really a demographer but rather a sociologist who dabbles in demography' (p. 274). So his book is not aimed at population specialists but all those within and beyond academia and government who share an interest in how a series of interrelated major demographic changes in New Zealand prompt searching questions about their future. In seeking answers, Spoonley argues, New Zealanders should be more aware of demographic forecasts of population growth and decline, changing birth and death rates, major family and generational reformation, especially ageing, and internal and international migration that all combine to present a complex scenario that can be viewed in a variety of ways. As an apt dedication to his father and grandson illustrates, whether different generations of New Zealanders will perceive these developments as a crisis or opportunity and how prepared politicians and their electorate will be to plan for a rapidly changing future is open to a debate this author wants to instigate.

In keeping with the tone of his acknowledgements, Spoonley stresses that he is primarily concerned with population trends and issues not a technical discussion of the generation or analysis of statistical material. Consequently, his book is generally free from jargon and the profusion of descriptive statistics is user-friendly. This is particularly noticeable in Chapter Two where he introduces what he sees as the basics of demographic analysis and shows how population numbers are generated mainly through regular sample surveys, most notably, large-scale censuses. He cautions that our local knowledge of demographic features is uneven and there is ample use of overseas, particularly OECD data and analysis that usefully complements local statistics. While media sources, which are used copiously throughout the text, serve to illustrate how they can clarify or obfuscate public and private anxieties and resentments in equal measure.

Having set out his overarching agenda specific items are looked at in turn. Subsequent chapters map out the changes in 'modern families' whose definition and functions have altered in myriad ways. He shows how an increase in sole parents, single person and childless households, delayed first births, and non-biological parenting reflects the impact of new technologies, economic factors, generational changes, and increased cultural diversity from regional and international mobility. Discussion of the interrelationship between changes in family formation and fertility patterns follows, and Spoonley contends there appears to be little governmental or public concern about the numbers showing declining birth rates and their effect on population growth. Mainly because he suggests there is little evidence that policy interventions could easily change this even if desired. Which cannot be said of migration flows that remain significantly important in compensating for natural decreases in population growth and are often contentious, especially under current Covid conditions.

Given the author's longstanding sociological interest in migration, racism and ethnicity this book contains well-crafted appraisals of these subjects (in chapter 5) and a welcome linked 
section on the effects of New Zealanders sojourning or settling overseas. New Zealand's demographic size meant it was able historically to obtain most of its migrants from a favoured very narrow British source in a competitive global market. International political, economic, and juridical influences, however, saw diversification and deregulation becoming the new ideological policy mantra and immigration was no exception. Thus, post-1980s migrants arrived with an ever-increasing range of origins with few constraints on new arrivals to acquire citizenship and very liberal rules on holding dual national status. Moreover, as Spoonley emphasises, the New Zealand state sought to 'pick and choose' largely skilled migrants since earlier Maori and Pasifika rural to urban migration largely filled other employment slots. These changes, as he recognises, had far-reaching ramifications for not only bicultural and multicultural issues but also how changing population numbers affected cross-generational relations and perceptions within different regions. Most notably between Auckland, other cities, and their rural hinterlands - not forgetting the significant diverse New Zealand diaspora residing in other parts of the world.

Subsequent discussion (in chapters 7 to 9) of the rise or fall of regions, the rapid growth of primate city Auckland and the size and configuration of an ageing 'majority' population brings us closer to Alba's book and arguably presents the most challenging features of recent demographic change in Aotearoa New Zealand - with the added prefix being indicative of this. These sections of the book neatly highlight how, despite the continued importance of agricultural production and predominantly rural tourism as key platforms of economic progress and security, contrasting patterns of growth and decline of regional density and corresponding changes in median age and ethnic profiles often provoke heated conversations about geographic and generational divisions.

This is a well-worn narrative for the specialists but bears repeating given, as Spoonley highlights, the stereotypical imagery freely used in popular parlance and some media about Aucklanders and aged winners and youthful losers. Careful analysis ought to point to more measured policy discussions about boosting the regions and managing Auckland's burgeoning and increasingly heterogeneous population alongside equally weighty issues concerning the workforce and health and superannuation implications of an ageing population. He stresses the dangers of judgemental perceptions of segregated communities and ghettos or political jibes about 'OK, Boomer'. Yet I wonder if the author's enthusiasm for, to use his words, the superdiversity of this supercity, paradoxically runs the danger of magnifying a labelling process he seeks to finesse?

If one just looks at the numbers, and you need to be careful about where you draw the boundaries, you can accurately state, as the author does, that Auckland is the fourth most diverse city globally in terms of its proportion of migrants, ahead of Los Angeles, London, and Melbourne. But is this ranking just a reflection of abstract percentages? How many of New Zealand's diaspora living in these overseas conurbations, including Aucklanders, would agree it has the same sociocultural vibe as their current abodes? Auckland is certainly growing apace but is it sizeable and dense enough to be called 'another country' when so many Kiwis still share a somewhat similar suburban lifestyle? Maybe, yet LA County and metropolitan London are almost twice the size of the total New Zealand population and Melbourne is close to the Aotearoa national figure. Talk of almost 200 ethnic groups in Auckland also sounds significant, or alarming or invigorating depending on the observer. Yet what needs detached consideration is whether they are socially interacting communities or 
population aggregations of differing dimensions, some of which are very small and dispersed. Nonetheless, if we are highlighting public perceptions and prejudices about what should be rather than what is, the author has a point when emphasising the political import of geographic divisions and how they are compounded by other demographic factors. Not least when addressing debates surrounding generational differences. He stresses that recent exchanges about age cohorts often ignore multiple intragenerational differences when judging political and sociocultural privileges and disparities between 'boomers', 'millennials' and other alphabetically named generational categories. Thus, ironically, if diversity is at the centre of racial and ethnic controversy it is frequently disregarded in supposed generational wars.

\section{The Great Demographic Illusion?}

These issues loom large in Richard Alba's latest book and he steers his way through contested conceptual and political waters with admirable clarity. His acknowledgements also reveal autobiographical links between sociology and demography and a keen interest in what lies behind public statistics. Relations between the author and population specialists seem cordial and respectful but, as his title suggests, there is a far keener critical edge to Alba's more conspicuous sociological imagination. This book was written pre-Covid after Obama had been replaced by Trump but before the tumultuous events that heralded Biden's ascendancy. Yet far from dating this text these events give it added weight. Why Trump was initially elected and why Republicans still voted for him in considerable numbers in 2020 is still being deliberated, as the book outlines (in Chapter 2). Echoing some of Spoonley's concerns, the juxtaposition of racial, ethnic, and generational projections was politically very influential. As Alba points out a common populist narrative depicts a 'majority-minority nation' in which white senior citizens are now outnumbered by nonwhite children. Soon, therefore, or so the story goes, the USA will experience a racial and ethnic demographic upheaval of possibly seismic proportions. This Manichean perspective can, of course, be viewed in numerous ways, pun intended. Alba is careful to stress, particularly in Chapter 3, that power relations, economic status and political positioning are not simply a matter of numbers, yet population size has electoral weight. So seemingly detached calculations about hypothetical futures become impassioned narratives about whether 'the majority' will 'become a sociological, not just a numerical minority, vulnerable to the power of others' (p.56). How did this eventuate? In the following chapters, Alba summarises how, unlike New Zealand, the USA census still asks directly if you are white or non-white, although more in tune with recent local practice the opportunity to respond in more self-designated and variegated ways has been introduced in the last two decades.

Historically, the notorious American racist 'one-drop rule' meant that any degree of what was then called 'negroid' ancestry consigned you to the 'non-white category'. Local and American censuses no longer measure 'blood' quantum (which New Zealand used to do in Maori surveys) but seek to elicit what your self-reported socio-cultural identity is. Yet USA respondents are still classified in binary terms if they indicate any degree of identification with non-Anglo ancestry. Why? The author emphasises that the Census Bureau is constrained by legal, bureaucratic, and political dictates and had to follow a ruling by the Office of Management and Budget in 2000 to treat all 'mixed-race' Americans as part of the non-white minority. Ironically, partly driven by civil rights and multicultural advocates 
seeking affirmative action for this category of persons. For Alba, consigning all 'persons of colour' into the category 'non-white' perpetuates a zero-sum majority/minority illusory myth. This is most evident, he argues, when one examines the categorisation and lives of Americans with mixed minority-white parentage. In chapter 5 a qualitative and quantitative survey of studies of the socioeconomic positions, affiliations, including intermarriage, and identities of those from mixed-minority backgrounds suggests that the offspring of mixed couples are becoming increasingly assimilated into a multihued and multicultural mainstream. A development, which in some ways resembles earlier waves of immigrants moving into a bi-racially separated society but in important respects is significantly different. A new non-zero-sum form of assimilation into the mainstream, in the author's view, best describes the current and future trends of intermixing for increasing numbers of Americans with composite heritages. With the striking exception that despite some signs of the barriers between Afro-Americans and others starting to breakdown, consistently high rates of poverty and incarceration, for example, suggest historically embedded inequalities remain entrenched.

Doesn't this indicate that achieving 'whiteness' is still the key to social, economic and political achievement in the United States? Alba's responds to this question by prudently reviewing the competing theoretical and empirical merits of critical race and old and new assimilation theories and restating his position more fully (in chapters 6 and 7). He underlines the importance of the former perspective in explaining the persistence of African American inequality but is less convinced of its applicability to explaining the historical boundaries erected against non-Anglo European arrivals. He suggests their 'racial' distance from other whites is exaggerated and the importance of class and religious differences is underestimated. Consequently, assimilation theories are found more convincing with the important proviso, especially in recent decades, that instead of assuming that minorities are forced to become like the majority, even metaphorically ' whiter', these processes are better explained by his non-zero-sum assimilation theory. This 'presumes changes in social structures that open-up space for formerly marginalized minorities to enter the mainstream without appearing to threaten the status of established groups' (p.164). America is witnessing forms of inclusion that do have twentieth-century parallels, but this is mainly due, Alba stresses, to moves across birth cohorts, as older ones leave spaces for younger ones to enter them, and upward mobility among previously marginalised or excluded groups do not have to be compensated for by downward movement of those above them. Consequently, monoculturalism and whiteness is not a prerequisite for achievement. Alba readily concedes that aggregates often conceal stratified differences and regional disparities in American cities and rural hinterlands. While the persistent poverty, racism and discrimination experienced by many African and Native Americans, and the scapegoating of especially unauthorised Mexican immigrants, belie the fluid character of the experiences and identities of mixed individuals that he highlights. There is, therefore, still a coexistence between new and old zero-sum and non zero-sum assimilatory trajectories and on-going parallel renovation of racial and ethnic separatist barriers. Hence major questions remain about how entry into the mainstream could be expanded, especially in a period of widening financial inequalities and tighter upward mobility possibilities, even for those who can gain the educational credentials required to achieve this. 
In his concluding chapters, Alba examines if and how economic inequality could be reduced, racist exclusion might be redressed and whether legal security can be forthcoming for current and future unauthorised minority generations. Social class divisions must be addressed through wealth redistribution, more progressive taxation and improving educational systems, while anti-racist and affirmative policies are required to halt the persistence of sharp, stratified racial boundaries that ethnic blending is only slowly eroding. Widespread current fears and anger about deep-seated inequalities are, therefore, hardly misplaced. However, those who predict a future of changing race fixated binary fortunes, and they are evident, Alba notes, on both extremes of the political spectrum, are oversimplifying a highly complex situation. If you accept his overall analysis, and I for one, found much of it persuasive, a 'white' political majority will remain in place for the foreseeable future because projections are not strictly a product of fertility, mortality, and local and global migration. This is the great demographic illusion. Society is not neatly split between two ethno-racial blocs, one of which is declining rapidly, and the processes that are producing these changes are not primarily demographic. The future is mainly shaped by social and economic forces and policies (or the lack of them) that influence the opportunities for disadvantaged 'whites' and 'non-whites' to advance economically and the character of increasingly mixed relations across ethno-racial boundaries.

\section{Conclusions}

Both these books highlight the importance of the close relationship between demography and sociology. These sibling disciplines, to quote local demographer lan Pool in a recent reflection on their relationship, are similarly concerned with 'social dynamics, structures and change' (Pool, 2016:146), although often from different perspectives since family relations can be supportive and fractious. Demography for him is not atheoretical or unconcerned with the qualitative small-scale intricacies of social life, but it is primarily an applied, macro quantitative science (and quite possibly art) that seeks to elicit collective, aggregated population trends. So, at least for Pool, demography primarily provides a first-order view of life's great issues and relies on its kindred disciplines for what he calls 'higher order' levels of explanation (Ibid:164). Interdisciplinary shifts towards population studies tend to reflect this. These leanings are particularly evident in Spoonley's rather brief concluding chapters that skim over weighty analytical questions that lurk beneath the surface. A result, one suspects, of not wishing to scare apocryphal anti-intellectual horses with too much theory. Summing up, he reiterates that New Zealanders should be talking about population matters and, better still, planning for future eventualities. His conversation topics are deceptively straightforward. How big should the national population be? Are we concerned if Auckland continues to grow, and some regions do not? Should migration, in and out, compensate for declining natural increase? How do we deal with the process of ageing and an imbalance of workers and dependants? Do Maori and Pasifika merit special attention given many of their economic and social indicators show persistent inequalities? Above all, given the key focus of his book, is our demographic data, particularly censuses, fit for purpose for a new New Zealand? From the vantage point of emulating a demographic imagination, Spoonley is inclined to say yes but remains understandably ambivalent about if and how New Zealanders have the political will to tackle the above questions. His scepticism ultimately derives from what he sees as deficiencies in outmoded policy agencies and inadequate systems of political representation. I partly agree. But I think the problems go deeper and 
running counter to a consistent theme in Spoonley's book they are as much about the past as the future. To say that many of our ideas and institutions are outdated and deficient may be correct but are the current and forecast demographic problems he describes completely new, and do they require entirely novel solutions? Most issues remain inextricably entangled in the near or distant past since our way forward so often relies on confronting historical myths and events and seeking to resolve perennial philosophical and conceptual questions that sociology and demography will always contend with. This is well illustrated in Alba's text.

Regrettably, I expect most New Zealanders will not read his book despite an increasing influence of the United States in our media and the readily observable theoretical and ideological local impact of American academic and popular debates, if that is not too polite a word, about racial and ethnic distinctions. Much of this discussion rests on a priori prioritisations of 'race' over 'ethnicity' or vice versa or a conflation of these concepts that does not distinguish between sociocultural boundaries and biological/phenotypical hierarchies. And protagonists often fail to recognise or simply ignore that ethnic differences can be just as exclusive and oppressive as racial barriers (for discussion see, for example, Valdez, and Golash-Boza, 2017). But whether this is the case can only be established empirically with an appreciation of time and place (Siebers, 2013). These exchanges may not have reached the same political intensity here and as noted earlier, New Zealand presents important historical and current differences in the size and composition of its population categories. Nonetheless, resentful or triumphal assertions of declining majority prospects are not hard to find. While claims of racism are seen everywhere. So reading both books in tandem is recommended. Like Alba, Spoonley wants to move beyond 'old' assimilation theories and state policies that assumed minorities had to merge into the majority to achieve a modicum of advancement and acceptance, and, as they both acknowledge, such views are still far from redundant in official and popular parlance.

It is interesting, therefore, briefly to speculate on whether Alba's theory of new non-zero sum assimilation into a more diverse mainstream has any application in New Zealand, particularly as Kivisto, for example, recently notes, comparative sociological theories of assimilation that situate multiculturalism within them have not been fully articulated (Kivisto, 2017). Alba's cumulative research and writing, as Kivisto reminds us, is about how boundaries divide and demarcate populations and the degree to which they can be crossed, blurred, or shifted. In so doing putative ethno-racial categories and identities are 'preserved, enhanced, undermined or reconfigured' (Ibid:1428). Historically, New Zealand did not experience a mass, post Second World War diverse immigration of 'white ethnics', but British migrants still had to fit in. And arrivals less proximate to the majority were compelled to integrate. If indeed, this was achievable or desired. Recent diverse inflows, however, do bear some resemblance to the American experience. Admittedly, on a different scale, nonetheless, the effects on a small population base amplify boundary perceptions. Given the state's ability to selectively filter skilled intakes and the continuance of less qualified migrant workers being recruited for jobs that many New Zealanders would not contemplate, one could argue that occupational spaces are being filled without zero-sum consequences for the local-born. Values surveys, whose American equivalents Alba utilises, also indicate that most New Zealanders may still prefer those closest to them in ancestry, culture and appearance as partners, friends, or neighbours. While many settled and newly arrived 
migrants feel more comfortable living together in residential areas that provide support and familiar experiences of their origins. But there is evidence of increased mixing and tolerance of different lifestyles and beliefs across borders. Thus, separation and mingling are occurring simultaneously outside and within mainstream boundaries (Pearson, 2019).

What is distinctive in the old and new New Zealand, as Spoonley mentions when discussing immigration, is viewing indigenous/settler relations through a binary lens. Alba does allude to some similarities between the situation of African Americans and on reserve Native Americans, but it is the racialised post-slave divide that he sees as the most intractable problem in America? The starkness of this boundary, as noted earlier, stems from persistent social and economic immobility, residential distance, and a lack of moral elevation in the eyes of others, most graphically shown in beliefs about perceived immutable phenotypical and cultural differences. All too visible indicators of Maori regionalised poverty and disproportionately high levels of incarceration lend weight to a similar pessimism. Can one say, therefore, that non-zero migrant ethnic assimilation into the mainstream will co-exist with persistent relative inequalities between Maori and other racialised categories of people in a new New Zealand? One might argue there are grounds for optimism in growing trends of demographic and social intimacy, stratified but tangible signs of relative occupational and educational advancement depending on the time and place contexts one chooses, and often subtle (and possibly patronising) nuances of increased respect for different socio-cultural mores. Detractors, rightly, will point to the dangers of fostering complacency fuelled by facile assessments of New Zealand exceptionalism. Emphasising bicultural issues of colonialism, sovereignty and self-determination must be considered before multicultural musings. But there are also hazards in essentialising racial and colonial structural forces that seem to offer no way out of historical cul de sacs. This brings us back to maxims that may be unexceptional for specialists but indispensable to repeat for others. How we theoretically assess intricate configurations and the political assumptions we draw upon in the process is the nub of things. The use and misuse of population categorisation lie at the heart of this equation (see Kukutai and Broman, 2016). The messy and vibrant everyday lived experience of diversity, super or otherwise, needs to be analytically distinguished from the political processes that seek to institutionalise it, for good or ill, by putting people into over-neat boxes and then using them to shape public policy (Malik, 2005).

Despite decades of social constructionist theorising and empirical inquiry in the social sciences and humanities, 'races', ethnicities, women and men, generations and socioeconomic entities some are prepared to call classes, continue to be conceived as distinct communities and cast as actors with identities (see, for example, Brubaker and Cooper, 2000). Journalists, commentators and policymakers, let alone those proverbial persons in the street, routinely frame accounts of conflict and co-operation as the interaction of internally homogeneous, externally bounded groups. In doing so, they, inadvertently or otherwise, contribute to the reification of categorical aggregates of individuals that often display as much multiplicity as they do uniformity. Politically this is understandable. One often has to present a common front to one's opponents. And if you must manufacture or accentuate this, so be it. But is this a useful explanatory strategy for seeking a better scholarly understanding and possible improvement of the human condition? Richard Alba provides us with a perceptive, lucid illustration of how sociological and demographic imaginations co-exist and productively play off one another to provide theories to argue against. Paul Spoonley, given his commendable but ambitious project to 
make population challenges accessible to the widest possible audience, tends to draw back from fully exploiting interdisciplinary relations. Yet he too aids our quest to explore how we might live together now and in the future.

\section{References}

Brubaker, R and Cooper, F. (2000). Beyond 'Identity, Theory and Society, 29(1), 1-47.

Kivisto, P. (2017). The origins of "new assimilation theory", Ethnic and Racial Studies, 40 (9), 1418-1429.

Kukutai, T.H. and Broman, P. (2016). From colonial categories to local culture: Evolving state practices of ethnic enumeration in Oceania, 1965-2014, Ethnicities, 16 (5), 689-711.

Malik, K. (2005). Making a difference: Culture, race and social policy, Patterns of Prejudice, 39, 361-378.

Pearson, D. (2019). National ties entwined: Civic and ethnic elements in New Zealand identity, in J.P. Trautsch, (ed.) Civic Nationalism in Global Perspective, Routledge, London, 129-152.

Pool, I. (2016). The Seminal Relationship between Demography and Sociology, New Zealand Sociology, 31 (3), 146-167.

Siebers, H. (2017). "Race" versus "ethnicity"? Critical race essentialism and the exclusion and oppression of migrants in the Netherlands', Ethnic and Racial Studies, 40 (3), 369-387

Valdez, Z. and Golash-Boza,T. (2017). U.S. racial and ethnic relations in the twenty-first century, Ethnic and Racial Studies, 40 (13), 2181-2209. 